\title{
BMJ Open Association between respiratory syncytial viral disease and the subsequent risk of the first episode of severe asthma in different subgroups of high-risk Australian children: a whole- of-population-based cohort study
}

Nusrat Homaira, ${ }^{1,2}$ Nancy Briggs, ${ }^{3}$ Christopher Pardy, ${ }^{3}$ Mark Hanly, ${ }^{4}$ Ju-Lee Oei, ${ }^{1,5}$ Lisa Hilder, ${ }^{1,4}$ Barbara Bajuk, ${ }^{6}$ Kei Lui, ${ }^{1,5}$ William Rawlinson, ${ }^{7,8,9}$ Tom Snelling, ${ }^{10,11,12}$ Adam Jaffe ${ }^{1,2}$

To cite: Homaira N, Briggs N, Pardy C, et al. Association between respiratory syncytial viral disease and the subsequent risk of the first episode of severe asthma in different subgroups of high-risk Australian children: a whole-of-population-based cohort study. BMJ Open 2017;7:e017936. doi:10.1136/ bmjopen-2017-017936

- Prepublication history for this paper is available online. To view these files please visit the journal online (http://dx.doi org/10.1136/bmjopen-2017017936).

Received 29 May 2017 Revised 11 September 2017 Accepted 15 September 2017

CrossMark

For numbered affiliations see end of article.

Correspondence to

Dr Nusrat Homaira;

n.homaira@unsw.edu.au

\section{ABSTRACT}

Objective To determine the contribution of respiratory syncytial virus (RSV) to the subsequent development of severe asthma in different subgroups of children at risk of severe RSV disease.

Settings The study was conducted in New South Wales (NSW), Australia.

Participants The study comprised all children born in NSW between 2000 and 2010 with complete follow-up till 31 December 2011. The cohort was divided into three subgroups: (1) non-Indigenous high-risk children: nonIndigenous children born preterm or born with a low birth weight; (2) Indigenous children: children of mothers whose Indigenous status was recorded as Aboriginal and/or Torres Strait Islander and (3) non-Indigenous standard risk children: all other non-Indigenous term children.

Primary outcome measure Risk of development of severe asthma in different subgroups of children who had RSV hospitalisation in the first 2 years of life compared with those who did not.

Design We performed a retrospective cohort analysis using population-based linked administrative data. Extended Cox model was used to determine HR and $95 \% \mathrm{Cl}$ around the $\mathrm{HR}$ for first asthma hospitalisation in different subgroups of children.

Results The cohort comprised 847516 children born between 2000 and 2010. In the adjusted Cox model, the HR of first asthma hospitalisation was higher and comparable across all subgroups of children who had RSV hospitalisation compared with those who did not. The HR $(95 \% \mathrm{Cl})$ was highest in children aged $2-3$ years; $4.3(95 \%$ $\mathrm{Cl} 3.8$ to 4.9$)$ for high-risk, 4.0 (95\% $\mathrm{Cl} 3.3$ to 4.8$)$ for Indigenous and 3.9 (95\% $\mathrm{Cl} 3.7$ to 4.1 ) for non-Indigenous standard risk children. This risk persisted beyond 7 years of age.

Conclusion This large study confirms a comparable increased risk of first asthma hospitalisation following RSV disease in the first 2 years of life across different subgroups children at risk.

\section{Strenghts and limitations of the study}

- To our knowledge this is the first study to demonstrate increased risk of first asthma hospitalisation following severe respiratory syncytial virus (RSV) disease concurrently in different subgroups of highrisk children at a population level.

- The study cohort comprised all children born in New South Wales between 2000 and 2010 which enabled us to determine the risk of asthma in different age groups extending beyond 7 years.

- This was an epidemiological study using linked administrative data and lacked information relating to factors like atopic predisposition and risk of subsequent asthma in this cohort, hence a causal association cannot be established for RSV hospitalisation.

\section{INTRODUCTION}

Background

Globally, acute lower respiratory infections (ALRIs) are a major cause of childhood morbidity and mortality. ${ }^{1}$ Early life respiratory viral infections have been linked to the development of subsequent asthma in children. ${ }^{2}$ This link has been particularly highlighted for early respiratory syncytial virus (RSV) infection in children which continues to be the major viral cause of childhood ALRIs in the first 2 years of life. ${ }^{3}$ It has been proposed that severe RSV infection in early childhood is associated with impaired lung function which persists beyond childhood and increases risk of recurrent wheezing and asthma at a later age of life. ${ }^{45}$ Asthma symptoms associated with severe RSV illness in first year of life can even persist in early adulthood. ${ }^{6}$ In addition, 
early RSV hospitalisation may also result in reduced lung function, even in the absence of asthma symptoms. ${ }^{6}$ Although there is some evidence that severe RSV disease and allergic sensitisation may be linked via interleukin (IL) -13/IL-4 gene polymorphisms, severe RSV infection in early childhood is possibly a consequence rather than a cause of a predisposition to severe reversible airway diseases. $^{78}$

\section{Objectives}

Australia has a high prevalence of paediatric asthma compared with other developed countries. ${ }^{9}{ }^{10}$ It is estimated that $21 \%$ of Australian children aged $0-15$ years have had a previous diagnosis of asthma, with $11 \%$ having a current diagnosis of asthma. ${ }^{11}$ In 2014, >13000 children aged 1-17 years presented to New South Wales (NSW) emergency departments for asthma, representing two-thirds of all hospital presentations across the state and yielding a significant burden on the healthcare system. ${ }^{12}$ The burden of RSV-associated lower respiratory tract infection (LRTI) is also very high in NSW, especially in children aged $<2$ years with an average annual direct healthcare cost of more than AUD 9 million in NSW alone. ${ }^{13}$ In addition, our previous study has demonstrated that the incidence of severe RSV disease was exceptionally high among children who were born preterm or with bronchopulmonary dysplasia and Indigenous children of NSW. ${ }^{13}$ It is, therefore, important to determine what, if any, contribution early severe RSV disease has on subsequent asthma hospitalisations in these subgroups of children at risk. While data exist on the high burden of RSV disease in these subgroups of children, to our knowledge, no study has investigated the contribution of RSV to subsequent asthma risk in different high-risk paediatric populations simultaneously. Such information will be important to inform targeted public health interventions aimed to lower the burden of severe asthma in Australian children.

To address this knowledge gap, we conducted a retrospective population-based cohort study designed to investigate the role of early RSV ALRI on the subsequent risk of development of severe asthma in different subgroups of children at risk in NSW.

\section{METHODS}

\section{Study design}

The study was a retrospective cohort analysis using linked population-based administrative data.

\section{Study site and study population}

The study was conducted in NSW, Australia comprising all children who were born in NSW born between 20002010 with complete follow-up till end of December


end of the follow-up period or in-hospital death, whichever was earlier. The birth cohort was divided into three subgroups:
1. Non-Indigenous high-risk children: Non-Indigenous children who (i) were born preterm (gestational age (GA) $<37$ weeks), (ii) were born at term with a birth weight of $<2500 \mathrm{~g}$.

2. Indigenous children: Children of mothers whose Indigenous status was recorded as Aboriginal and/or Torres Strait Islander in any of the data sets were considered to be Indigenous, including any born preterm or born with low birth weight.

3. Non-Indigenous standard risk children: All other non-Indigenous term children.

\section{Variables}

\section{Exposure variables}

The main exposure variable of interest was any episode of RSV coded hospitalisation in the cohort child from birth to 2 years of age, the peak age group for RSV hospitalisations. ${ }^{13}$ The International Classification of Diseases, 10th edition (ICD-10) primary diagnostic codes were used to identify RSV hospitalisations. Any hospitalisation with primary diagnostic codes associated with RSV pneumonia (J12.1), acute RSV bronchitis (J20.5), acute RSV bronchiolitis (J21.0), unspecified ALRIs (J22), unspecified acute bronchitis (J20.9) and unspecified acute bronchiolitis (J21.9) identified during RSV season (April-September in NSW) were included as RSV hospitalisations.

\section{Outcome variable}

The outcome variable of interest was first episode of asthma hospitalisation beyond the age of 2 years until the end of follow-up. All hospitalisations with primary diagnostic codes associated with asthma (J45), predominantly allergic asthma (J45.0), non-allergic asthma (J45.1), mixed asthma (J45.8), asthma unspecified (J45.9) and status asthmaticus (J46) or wheeze (R0.62) were considered as asthma hospitalisations.

\section{Confounders}

Confounders included in the analysis were based on the published literature and included maternal and child factors. ${ }^{14}$ Maternal variables were age at birth of the cohort child, parity, smoking during pregnancy and index of socioeconomic disadvantage of the mother's residential postcode at birth. Child factors included in the analyses were season of birth and sex of the child.

\section{Data sources}

The Centre for Health Record Linkage (CHeReL) (https://www.cherel.org.au) in NSW conducts linkage of various administrative health datasets for research purposes. CHeReL follows best practice probabilistic linkage ${ }^{15}$ to combine personal information to produce a person-based dataset using the NSW Perinatal Data Collection as the primary dataset to which all other datasets are linked. Each child was assigned a Patient Project Number and this was attached to the records in each source database. All other personal identifiers were removed from each of the datasets and the de-identified datasets with the unique identifier key were provided to 
the study investigators. One of the study investigators $(\mathrm{NH})$ combined records of the same child in the different data sets using the unique identifier key and undertook data cleansing.

The cohort was identified from the NSW Perinatal Data Collection in which all births in NSW are registered. Data relating to any episode of RSV and asthma in the cohort children were retrieved from the Admitted Patient Data Collection. This dataset also contained outcome of each hospitalisation including discharge status, death and need for transfer. The corresponding maternal, perinatal and sociodemographic factors for the cohort children were retrieved from the Perinatal Data Collection which was linked to the Admitted Patient data Collection. Socioeconomic disadvantage based on maternal post code of residence at the time of birth of the cohort child was measured using the Socioeconomic Index of Areas and Indices of Relative Socioeconomic Advantage and Disadvantage from the Australian Bureau of Statistics. ${ }^{16}$

\section{Bias}

This was a large whole-of-population based cohort study based on almost complete data sets. Out of 1264943 observations, there were $7432(0.5 \%)$ observations with one or more variables missing which were excluded from the final analyses.

\section{Study size}

This was a whole-of-population study including all children born in NSW between 2000 and 2010 so we did not perform any sample size calculation for our study.

\section{Quantitative variables}

The maternal age at birth of the cohort child was divided into five age groups including $<20$ years, 20-24 years, 25-29 years, 30-34 years and $\geq 35$ years; age group 25-29 years was considered as the referent group. IRSAD was divided into quintiles from least to most advantaged where level one was most disadvantaged and level five was most advantaged and level one was considered as the referent group. ${ }^{16}$

\section{Statistical analyses}

This was a cohort study where children were followed from birth and the risk of subsequent first asthma hospitalisation beyond the age of 2 years was determined using hazard analyses taking age of the child at asthma hospitalisation as the relevant time to event. As the hazard of subsequent asthma hospitalisation was non-proportional violating the proportionality hazard assumption of standard Cox model, we used an extended Cox model with time varying covariate to account for the non-proportionality. The age at asthma hospitalisation was split into 2-3 years, $3-5$ years, $5-7$ years and $>7$ years age groups and the interaction between baseline RSV risk and subsequent asthma hospitalisation was examined for the different age groups. Separate models were constructed for each of the predefined subgroup of children. The final multivariable model was adjusted for all available confounders mentioned in the method section. We estimated the HR and the 95\% CIs around the HR of first asthma hospitalisation after the age of 2 years for children with versus without any RSV hospitalisation in their first 2 years of life.

\section{RESULTS}

\section{Profile of the cohort}

The cohort comprised 847516 children born between 2000 and 2010. Of these, 437034 (52\%) were men and the mean age of the cohort at the end of the follow-up period was 73 months ( $\mathrm{SD} \pm 42$ months) (table 1). In total, 31831 (4\%) cohort children had at least one episode of RSV hospitalisation before the age of 2 years, of which $2405(7.5 \%)$ also had an episode of asthma hospitalisation after the age of 2 . The median age at first asthma hospitalisation was 3.2 years (IQR 2.5-4.4 years).

\section{Hazard for asthma hospitalisation}

In the adjusted multivariable Cox hazard model, the hazard of first asthma hospitalisation persisted to be double beyond the age of 7 years for children who were hospitalised with RSV in the first 2 years of life compared with those who were not (table 2). The adjusted HR for first asthma hospitalisation was highest for children between the ages 2 and 3 years. The adjusted HR at ages 2-3 years for non-Indigenous standard risk children was 3.9 (95\% CI 3.7 to 4.1 ), for high-risk children was 4.3 (95\% CI 3.8 to 4.9 ) and for Indigenous children was 4.0 (95\% CI 3.3 to 4.8 ). The risk of asthma hospitalisation at different ages was comparable across the different subgroups of children.

\section{DISCUSSION}

To our knowledge this is the first study to demonstrate increased risk of first asthma hospitalisation following severe RSV disease in different subgroups of high-risk children concurrently. Our findings, based on a very large population cohort of children followed up to 11 years of age, suggest that different subgroups of highrisk children, who developed RSV disease within the first 2 years of life continue to be at elevated risk of first asthma hospitalisation beyond the age of 7 years. The HR of first asthma hospitalisation was similar across all subgroups of children with the HR being four times higher at ages 2-3 years. Although premature children and Indigenous children aged $<2$ years are at almost 10 times higher risk of acquiring severe RSV disease compared with standard risk children, ${ }^{13}$ the similar hazard of subsequent asthma hospitalisation across different subgroups of children suggest that RSV might be the strongest predictor for developing subsequent severe childhood asthma. Thus, RSV might not only be the main aetiology for acute respiratory illness but also be an important contributor to chronic respiratory morbidity in children suggesting that interventions/therapies to prevent early severe RSV disease will help reduce the burden of subsequent paediatric 
Table 1 Perinatal and sociodemographic characteristics of cohort children born in NSW between 2000 and 2010

$\mathrm{N}=847516$

\begin{tabular}{|c|c|c|}
\hline \multirow[b]{3}{*}{ Exposures } & $\begin{array}{l}\text { Children with RSV hospitalisation in the } \\
\text { first } 2 \text { years of life }\end{array}$ & $\begin{array}{c}\text { Children without any RSV } \\
\text { hospitalisation in the first } 2 \text { years of } \\
\text { life }\end{array}$ \\
\hline & $\mathrm{n}=31831$ & $\mathrm{n}=815685$ \\
\hline & \multicolumn{2}{|c|}{ n (\%) } \\
\hline \multicolumn{3}{|l|}{ Maternal age (years) } \\
\hline$<20$ & $2102(6)$ & $32088(4)$ \\
\hline $20-24$ & $6342(19)$ & $113813(14)$ \\
\hline $25-29$ & $9022(28)$ & $227139(28)$ \\
\hline 30-34 & $9081(28)$ & $270626(33)$ \\
\hline$\geq 35$ & $5284(17)$ & 172019 (21) \\
\hline Maternal smoking during pregnancy & $8178(26)$ & $112584(14)$ \\
\hline Multiparity of the mother & $23211(73)$ & $470574(58)$ \\
\hline \multicolumn{3}{|l|}{ IRSAD } \\
\hline 1 (most disadvantaged) & $4032(13)$ & $78280(10)$ \\
\hline 2 & $4941(15)$ & $101577(12)$ \\
\hline 3 & $8405(26)$ & $189507(23)$ \\
\hline 4 & $7906(25)$ & $208681(26)$ \\
\hline 5 (most advantaged) & $6512(20)$ & $239566(29)$ \\
\hline Male sex of the baby & $18799(59)$ & $397005(49)$ \\
\hline \multicolumn{3}{|l|}{ Season of birth } \\
\hline Summer & $8121(26)$ & $195652(24)$ \\
\hline Autumn & $10470(33)$ & $198355(24)$ \\
\hline Winter & 7193 (23) & $207579(25)$ \\
\hline Spring & $6047(19)$ & $214099(26)$ \\
\hline High-risk children & $4902(15)$ & $60637(7)$ \\
\hline Indigenous children & 2960 (9) & $26732(3)$ \\
\hline $\begin{array}{l}\text { Non-Indigenous standard risk } \\
\text { children }\end{array}$ & $26172(82)$ & $741025(91)$ \\
\hline $\begin{array}{l}\text { Asthma hospitalisation beyond age } \\
\text { of } 2 \text { years }\end{array}$ & $2405(7.5)$ & 19974 (2) \\
\hline
\end{tabular}

IRSAD, Indices of Relative Socioeconomic Advantage and Disadvantage; NSW, New South Wales.

asthma/wheeze. While there are no effective antivirals or vaccines against RSV disease, at present, there is an effective anti-RSV monoclonal antibody (palivizumab) which can prevent severe RSV disease in high-risk infants including those born preterm and with chronic lung and heart conditions. ${ }^{1718}$ Studies have shown that palivizumab can also prevent subsequent recurrent wheeze in preterm children. ${ }^{19}{ }^{20}$ However, use of palivizumab remains limited in Australia and there is no standardised national guideline. Considering the potential beneficial effect of palivizumab on severe RSV diseases and subsequent recurrent wheeze in children, there is a need for revisiting its effectiveness and standardising guidelines with inclusion of Indigenous children as high-risk.

The risk of first asthma hospitalisation in our cohort children who had severe RSV disease leading to hospitalisation in their first 2 years of life was significantly higher across all the age strata. It is possible that many of the first asthma hospitalisation within ages 2-3 and $3-5$ years in our analysis may have been due to recurrent wheeze. Indeed diagnosis of asthma in children aged $<5$ years is challenging. The Global Initiative for Asthma guideline suggest that symptoms including frequent episodes of wheeze, activity-induced cough or wheeze, nocturnal cough without viral infections in periods which persist beyond 3 years of age are suggestive of asthma in children $<5$ years of age. ${ }^{21}$ In addition, RSV disease has been associated with increased risk of persistent wheezing in children. ${ }^{52}$ However, the risk of first asthma hospitalisation in this cohort was also significantly higher at ages 5-7 years and beyond 7 years of age. Another longitudinal study done in the UK had also reported that the odds 
Table 2 HR for first asthma hospitalisation beyond the age of 2 years in different subgroups of children who had severe RSV disease in the first 2 years of life compared with those who did not: NSW 2000-2010

\section{Non-Indigenous standard risk \\ children}

High-risk children

Indigenous children

\begin{tabular}{|c|c|c|c|c|c|c|}
\hline $\begin{array}{l}\text { Age at first asthma } \\
\text { hospitalisation (years) }\end{array}$ & $\begin{array}{l}\text { Adjusted HR } \\
(95 \% \mathrm{Cl})\end{array}$ & $\begin{array}{l}\text { Unadjusted HR } \\
(95 \% \mathrm{Cl})\end{array}$ & $\begin{array}{l}\text { Adjusted HR } \\
(95 \% \mathrm{Cl})\end{array}$ & $\begin{array}{l}\text { Unadjusted HR } \\
(95 \% \mathrm{Cl})\end{array}$ & $\begin{array}{l}\text { Adjusted HR } \\
(95 \% \mathrm{Cl})\end{array}$ & $\begin{array}{l}\text { UnAdjusted } \\
\text { HR }(95 \% \mathrm{Cl})\end{array}$ \\
\hline $2-3$ & $\begin{array}{l}4.1 \\
\text { (3.9 to } 4.4)\end{array}$ & $\begin{array}{l}3.9 \\
\text { (3.7 to } 4.1)\end{array}$ & $\begin{array}{l}4.7 \\
(4.2 \text { to } 5.3)\end{array}$ & $\begin{array}{l}4.5 \\
(4.0 \text { to } 5.1)\end{array}$ & $\begin{array}{l}4.1 \\
\text { (3.4 to } 4.9)\end{array}$ & $\begin{array}{l}4.0 \\
\text { (3.3 to } 4.8)\end{array}$ \\
\hline $3-5$ & $\begin{array}{l}3.0 \\
(2.9 \text { to } 3.2)\end{array}$ & $\begin{array}{l}2.8 \\
(2.7 \text { to } 3.0)\end{array}$ & $\begin{array}{l}3.1 \\
(2.7 \text { to } 3.5)\end{array}$ & $\begin{array}{l}3.0 \\
(2.7 \text { to } 3.4)\end{array}$ & $\begin{array}{l}2.2 \\
(1.8 \text { to } 2.7)\end{array}$ & $\begin{array}{l}2.2 \\
(1.8 \text { to } 2.6)\end{array}$ \\
\hline $5-7$ & $\begin{array}{l}2.4 \\
\text { (2.2 to } 2.7)\end{array}$ & $\begin{array}{l}2.3 \\
\text { (2.1 to } 2.5 \text { ) }\end{array}$ & $\begin{array}{l}2.6 \\
\text { (2.1 to } 3.2)\end{array}$ & $\begin{array}{l}2.6 \\
(2.1 \text { to } 3.2)\end{array}$ & $\begin{array}{l}2.6 \\
(1.9 \text { to } 3.4)\end{array}$ & $\begin{array}{l}2.5 \\
(1.9 \text { to } 3.3)\end{array}$ \\
\hline$>7$ & $\begin{array}{l}2.8 \\
(2.4 \text { to } 3.2)\end{array}$ & $\begin{array}{l}2.6 \\
(2.3 \text { to } 3.0)\end{array}$ & $\begin{array}{l}3.5 \\
(2.7 \text { to } 4.5)\end{array}$ & $\begin{array}{l}3.4 \\
(2.6 \text { to } 4.3)\end{array}$ & $\begin{array}{l}2.0 \\
(1.4 \text { to } 3.1)\end{array}$ & $\begin{array}{l}1.9 \\
(1.2 \text { to } 2.9)\end{array}$ \\
\hline
\end{tabular}

*HR after adjusting for mother's age at birth of the cohort child, parity, maternal smoking during pregnancy, index of socioeconomic disadvantage of the mother's residential postcode at birth, season of birth and sex of the child.

NSW, New South Wales; RSV, respiratory syncytial virus.

of doctors diagnosed asthma beyond the age of 7 was double for children who had RSV hospitalisation in the first year of life compared with the those who did not. ${ }^{22}$ Other studies have also noted that risk of subsequent asthma following early RSV illness can persist until 11 years of age ${ }^{5}$ and even in adulthood. ${ }^{6}$ It is believed that early severe lower RSV infection may cause airway remodelling and impair development of the growing lung which persists in later life. ${ }^{23}$ Even mild RSV disease may lead to residual impaired lung function in children up to the age of 13 years. ${ }^{5}$

An important limitation of the study is that our exposure and outcome variables of interest were coded RSV and asthma hospitalisations; it is possible that some hospitalisations were misclassified because routine laboratory confirmation of RSV may not be a standard clinical practice in some hospitals and the diagnosis of asthma in younger children is a challenge. This was a population-based study using administrative data where diagnosis of diseases was based on ICD codes and any possible error with the coding system was beyond our control. We considered all unspecified episodes of bronchiolitis and bronchitis identified during RSV season which may have led to overestimation or underestimation (as laboratory confirmation of RSV diseases is not necessarily a standard clinical practice) of the effect. However, our previous analysis $^{13}$ suggests that all-cause-associated ALRI-coded hospitalisations in children aged $<2$ years during the RSV season follows a similar trend as RSV coded hospitalisation and RSV notification data which suggests that most paediatric ALRI hospitalisations during the RSV season are likely due to RSV. We did not have access to any information regarding atopic predisposition of children; it is likely that many children hospitalised with asthma were atopic. If early severe RSV disease is also a manifestation of atopic predisposition, it is possible that the observed relationship between RSV and asthma is not causal. However, other studies suggest that the association between asthma and RSV is independent of atopic history. ${ }^{24}{ }^{25}$ As this was an epidemiological study, causality of the association between RSV and asthma cannot be confirmed, but the findings are comparable to other studies adding to the body of evidence that a strong association exists. We did not have access to ambulatory care data so could not assess the association between less severe forms of RSV infection and asthma not requiring hospitalisation. In our cohort, there were only 335 hospitalisations coded as associated with any other viral ALRI in the first 2 years of life, compared with 31831 RSV-associated ALRI hospitalisations; we therefore did not investigate association between other virus-specific ALRI and asthma. This work compliments the apparent association between RSV disease with the subsequent development of asthma ${ }^{5}$ while infections with other viruses like rhino and influenza viruses ${ }^{26}$ are more clearly associated with exacerbations of asthma. In addition, even if any association exist, their contribution to asthma is likely to be comparatively small.

Our study confirms that hospitalisation for severe RSV disease in the first 2 years of life is associated with the subsequent hospitalisation for first episode of asthma hospitalisation in Australian children. While there are currently no effective antivirals or vaccines targeting RSV, several vaccines are being evaluated in clinical trials. ${ }^{27}$ Once an effective vaccine becomes available, long-term follow-up of children to evaluate the impact on subsequent asthma development will help define the causal pathway of RSV and asthma, particularly in the high-risk groups. Meanwhile, more conservative preventive strategies such as frequent hand washing ${ }^{28}$ targeted to prevent transmission of RSV disease may also have the added benefit of reducing the burden of asthma in children.

\section{Author affiliations}

'Department of Paediatrics, Faculty of Medicine, School of Women's and Children's Health, University of New South Wales, Sydney, New South Wales, Australia 
${ }^{2}$ Respiratory Department, Sydney Children's Hospital, Sydney, Australia

${ }^{3}$ Stats Central, Mark Wainwright Analytical Centre, University of New South Wales, Sydney, New South Wales, Australia

${ }^{4}$ Centre for Big Data Research in Health, University of New South Wales, Sydney, New South Wales, Australia

${ }^{5}$ Department of Newborn Care, Royal Hospital for Women, Sydney, Australia ${ }^{6}$ NSW Pregnancy and Newborn Services Network, Sydney Children's Hospitals Network, Randwick, New South Wales, Australia

${ }^{7}$ Serology and Virology Division, SEALS Microbiology, Prince of Wales Hospital, Randwick, New South Wales, Australia

${ }^{8}$ School of Medical Sciences, University of New South Wales, Sydney, New South Wales, Australia

${ }^{9}$ School of Biotechnology and Biomolecular Sciences, University of New South Wales, Sydney, New South Wales, Australia

${ }^{10}$ Princess Margaret Hospital for Children, Perth, Australia

${ }^{11}$ Wesfarmers Centre of Vaccines and Infectious Diseases, Telethon Kids Institute,

University of Western Australia, Perth, Australia

${ }^{12}$ Menzies School of Health Research, Charles Darwin University, Darwin, Australia

Acknowledgements The authors would like to thank Sydney Children's Hospital foundation and Rotary Club of Sydney Cove for their continued support in our research endeavours. They are grateful to Respiratory Department of Sydney Children's Hospital, Randwick and Virology Research Laboratory of Prince of Wales Hospital, Randwick for their cooperation. They thank the Aboriginal Health and Medical Research Council and Ministry of Health, NSW. They also thank the babies and their families, the nursing and midwifery, obstetric and medical records staff of the obstetric and children's hospitals in NSW and the ACT.

Contributors $\mathrm{NH}$ and AJ, conceived and designed the study. NH, NB and CP, responsible for analysing the data. NH, drafted the manuscript. TS, WR, KL, J-L 0 , $\mathrm{LH}$ and $\mathrm{BB}$, provided technical feedback with design, analyses and drafting of the manuscript.

Funding This work was supported by The Rotary Club of Sydney Cove and the Cerebral Palsy Alliance of Australia. The funding organisation had no role in the study design, analyses or drafting of the manuscript.

\section{Competing interests None declared.}

Patient consent Detail has been removed from this case description/these case descriptions to ensure anonymity. The editors and reviewers have seen the detailed information available and are satisfied that the information backs up the case the authors are making.

Ethics approval NSW Population and Health Service Research (HREC/09/ CIPHS/33;2009/05/155) and the Aboriginal Health and Medical Research Council Ethics (726/10).

Provenance and peer review Not commissioned; externally peer reviewed.

Data sharing statement This study used linked administrative data. These data are available to researchers on request and subject to approval from the relevant data custodians and ethics committees, and via linkage conducted by the NSW Centre for Health Record Linkage (http://www.cherel.org.au). There are no additional data available.

Open Access This is an Open Access article distributed in accordance with the Creative Commons Attribution Non Commercial (CC BY-NC 4.0) license, which permits others to distribute, remix, adapt, build upon this work non-commercially, and license their derivative works on different terms, provided the original work is properly cited and the use is non-commercial. See: http://creativecommons.org/ licenses/by-nc/4.0/

(C) Article author(s) (or their employer(s) unless otherwise stated in the text of the article) 2017. All rights reserved. No commercial use is permitted unless otherwise expressly granted.

\section{REFERENCES}

1. Nair H, Simões EA, Rudan I, et al. Global and regional burden of hospital admissions for severe acute lower respiratory infections in young children in 2010: a systematic analysis. Lancet 2013;381:1380-90.
2. Kusel MM, de Klerk NH, Kebadze T, et al. Early-life respiratory viral infections, atopic sensitization, and risk of subsequent development of persistent asthma. J Allergy Clin Immunol 2007;119:1105-10.

3. Nielsen HE, Siersma V, Andersen S, et al. Respiratory syncytial virus infection-risk factors for hospital admission: a case-control study. Acta Paediatr 2003;92:1314-21.

4. Schauer U, Hoffjan S, Bittscheidt J, et al. RSV bronchiolitis and risk of wheeze and allergic sensitisation in the first year of life. Eur Respir J 2002;20:1277-83.

5. Stein RT, Sherrill D, Morgan WJ, et al. Respiratory syncytial virus in early life and risk of wheeze and allergy by age 13 years. Lancet 1999;354:541-5.

6. Sigurs N, Aljassim F, Kjellman B, et al. Asthma and allergy patterns over 18 years after severe RSV bronchiolitis in the first year of life. Thorax 2010;65:1045-52.

7. Kuehni CE, Spycher BD, Silverman M. Causal links between RSV infection and asthma: no clear answers to an old question. Am J Respir Crit Care Med 2009;179:1079-80.

8. Thomsen SF, van der Sluis S, Stensballe LG, et al. Exploring the association between severe respiratory syncytial virus infection and asthma: a registry-based twin study. Am J Respir Crit Care Med 2009;179:1091-7.

9. Australian Bureau of Statistics. Australian health survey: first results, 2011-12. Canberra: Australian Bureau of Statistics, 2012.

10. Goeman DP, Abramson MJ, McCarthy EA, et al. Asthma mortality in Australia in the 21st century: a case series analysis. BMJ Open 2013;3:e002539.

11. Poulos LM, Toelle BG, Marks GB. The burden of asthma in children: an Australian perspective. Paediatr Respir Rev 2005;6:20-7.

12. Health NSW. Asthma hospitalisations, 2015 http://www.healthstats. nsw.gov.au (accessed 17 July 2015).

13. Homaira N, Oei JL, Mallitt KA, et al. High burden of RSV hospitalization in very young children: a data linkage study. Epidemiol Infect 2016;144:1612-21.

14. Sears MR, Holdaway MD, Flannery EM, et al. Parental and neonatal risk factors for atopy, airway hyper-responsiveness, and asthma. Arch Dis Child 1996;75:392-8.

15. Irvine KA, Taylor LK. The Centre for Health Record Linkage: fostering population health research in NSW. N S W Public Health Bull 2011;22:17-18

16. Smithers LG, Searle AK, Chittleborough CR, et al. A whole-ofpopulation study of term and post-term gestational age at birth and children's development. BJOG 2015;122:1303-11.

17. Resch B. Palivizumab in preventing respiratory syncytial virusrelated hospitalization in high-risk infants. Expert Rev Pharmacoecon Outcomes Res 2008;8:529-38.

18. . Palivizumab, a humanized respiratory syncytial virus monoclonal antibody, reduces hospitalization from respiratory syncytial virus infection in high-risk infants. The IMpact-RSV Study Group. Pediatrics 1998;102:531-7.

19. Mochizuki H, Kusuda S, Okada K, et al. Palivizumab prophylaxis in preterm infants and subsequent recurrent wheezing. Six-year followup Study. Am J Respir Crit Care Med 2017;196:29-38.

20. Simoes EA, Groothuis JR, Carbonell-Estrany X, et al. Palivizumab prophylaxis, respiratory syncytial virus, and subsequent recurrent wheezing. J Pediatr 2007;151:e1.:34-42.

21. Bateman ED, Hurd SS, Barnes PJ, et al. Global strategy for asthma management and prevention: GINA executive summary. Eur Respir J 2008;31:143-78.

22. Henderson J, Hilliard TN, Sherriff A, et al. Hospitalization for RSV bronchiolitis before 12 months of age and subsequent asthma, atopy and wheeze: a longitudinal birth cohort study. Pediatr Allergy Immunol 2005;16:386-92.

23. Collins PL, Melero JA. Progress in understanding and controlling respiratory syncytial virus: still crazy after all these years. Virus Res 2011;162:80-99.

24. Holt PG, Sly PD. Interactions between RSV infection, asthma, and atopy: unraveling the complexities. J Exp Med 2002;196:1271-5.

25. Oddy $\mathrm{WH}$, de Klerk NH, Sly PD, et al. The effects of respiratory infections, atopy, and breastfeeding on childhood asthma. Eur Respir J 2002;19:899-905.

26. Minor TE, Dick EC, Baker JW, et al. Rhinovirus and influenza type A infections as precipitants of asthma. Am Rev Respir Dis 1976;113:149-53.

27. WHO-PDVAC. Status of Vaccine Research and Development of Vaccines for RSV, 2014. www.who.int/immunization/research/ meetings workshops/WHO_PDVAC_RSV.pdf.

28. Paes BA. Current strategies in the prevention of respiratory syncytial virus disease. Paediatr Respir Rev 2003;4:21-7. 